\title{
Hepatitis E Virus Papain-Like Cysteine Protease Inhibits Type I Interferon Induction by Down-Regulating Melanoma Differentiation-Associated Gene 5
}

\author{
Eunha Kim and Jinjong Myoung* \\ Korea Zoonosis Research Institute E Genetic Engineering Research Institute, Chonbuk National University, Iksan 54531, Republic of Korea
}

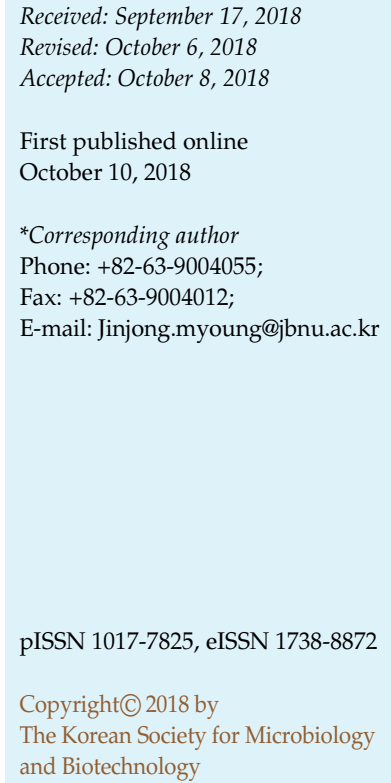

\begin{abstract}
Upon viral infection, the host cell recognizes the invasion through a number of pattern recognition receptors. Melanoma differentiation associated gene 5 (MDA5) and retinoic acidinducible gene-I (RIG-I) recognize RNA molecules derived from invading viruses, activating down-stream signaling cascades, culminating in the induction of the type I interferon. On the other hand, viruses have evolved to evade type I interferon-mediated inhibition. Hepatitis E virus has been shown to encode a few antagonists of type I interferon and it is not surprising that viruses encode multiple mechanisms of viral evasion. In the present study, we demonstrated that HEV PCP strongly down-regulates MDA5-mediated activation of interferon $\beta$ induction in a dose-dependent manner. Interestingly, MDA5 protein expression was almost completely abolished. In addition, polyinosinic polycytidylic acid (poly(I:C))- and Sendai virus-mediated activation of type I interferon responses were similarly abrogated in the presence of HEV PCP. Furthermore, HEV PCP down-regulates several molecules that play critical roles in the induction of type I IFN expression. Taken together, these data collectively suggest that HEV-encoded PCP is a strong antagonist of type I interferon.
\end{abstract}

Keywords: Hepatitis E virus, type I interferon, interferon beta, MDA5

\section{Introduction}

Hepatitis E virus (HEV) belongs to the Hepeviridae family. The genome of HEV is roughly $7.2 \mathrm{~kb}$ long and has a single-stranded positive-sense RNA molecule [1, 2]. The HEV genome encodes 7 non-structural proteins (open reading frame 1 (ORF1)), and 2 structural proteins (ORF2 and ORF3). Phylogenetic analysis shows that 4 genotypes (GT) of HEV infect humans, among which GT1 and GT2 are human-restricted and GT3 and GT4 are enzootic [3]. The first well-documented HEV outbreak was water-borne hepatitis in India, affecting approximately 29,000 people during the epidemic period of 1955-1956 [4]. It was originally thought to be caused by hepatitis A virus [5], however, extensive retrospective analysis of the stored sera from the 1955 Indian epidemic revealed that the pathology was non-A, non-B hepatitis. Subsequent studies established that a noble pathogenic entity was responsible [6, 7]. Reyes et al. successfully cloned and sequenced a part of the etiological agent [8]. The isolation and characterization of 'the culprit' led to renaming of the pathogen: hepatitis $\mathrm{E}$ virus with the ' $E$ ' standing for 'enteric' or 'endemic/ epidemic' [4]. Currently, HEV is known to account for 50,000 fatalities world-wide with over 20 million estimated annual infections, causing an especially high mortality rate in pregnant women (20 30\%).

Although the majority of HEV infections are self-limiting and asymptomatic $[9,10]$, in immunocompromised patients, $\mathrm{HEV}$ infections can establish chronic hepatitis, leading to fulminant hepatic failure, suggesting that host immunity against HEV plays an important role in the control of viral replication and virus-mediated pathology. As type I interferons (IFNs) are the first defense against viral infection [11-14], viruses have evolved to evade type I IFN responses [15-17]. Previously, we demonstrated that HEV methyltransferase (MeT) down-regulates RIG-I-mediated activation of type I IFN in dose-dependent manner [18]. Underlying molecular mechanism(s) are currently being 
sought. In addition, overexpression of papain-like cysteine protease (PCP) led to deubiquitination of RIG-I and TANKbinding kinase 1 (TBK1), thus blocking activation of RIG-Imediated down-stream IFN signaling [19]. The same group of researchers also showed that HEV X protein also inhibits RIG-I-dependent signaling [19]. Not only non-structural proteins but also ORF2 and ORF3 also displayed inhibitory effects on the type I IFN induction. For example, ORF2

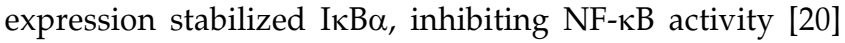
while ORF3 suppresses TLR3-mediated NF- $\mathrm{KB}$ activation [21]. HEV-encoded antagonists of the host innate immune responses have been revealing and the list keeps growing. Therefore, it is still possible that other HEV proteins regulate other immune genes involved in the type I IFN responses.

In the present study, we demonstrated that HEV PCP strongly inhibits MDA5-mediated induction of type IFN expression in a dose-responsive manner. RIG-I and TBK1mediated activation of IFN signaling was significantly inhibited as well and this is consistent with the previous reports. Interestingly, both polyinosinic-polycytidylic acid (poly(I:C))-induced and Sendai virus-mediated induction of IFN signaling were over $90 \%$ inhibited and phosphorylation of interferon regulatory factor 3 (IRF3) was strongly inhibited while MAVS- and IKKE-induced activation of IFN signaling cascades was not affected, suggesting specific target-oriented inhibition by PCP. Taken together, these data suggest that HEV PCP presents itself as a HEV-encoded antagonist which inhibits MDA5-mediated activation of IFN- $\beta$ induction as well as that of RIG-I.

\section{Materials and Methods}

\section{Cells and Reagents}

Human embryonic kidney 293T (HEK 293T) cells were maintained in Dubecco's Modified Eagle Medium (DMEM) supplemented with $10 \%$ fetal bovine serum (FBS, Gibco, USA) and 1\% penicillin/ streptomycin (Invitrogen, USA) [22-25]. The cells were grown in a humidifying incubator at $37^{\circ} \mathrm{C}$ with $5 \% \quad \mathrm{CO}_{2}$. Anti-FLAG antibody (M2) was purchased from Sigma-Aldrich. Anti-mouse antibody conjugated with horseradish peroxidase (HRP), antiglyceraldehyde-3-phosphate dehydrogenase (GAPDH), anti-IRF3, anti-phospho-IRF3 were purchased from Cell Signaling (USA). High molecular weight poly(I:C) was purchased from InvivoGen, USA. Polyethylenimmine (PEI) was purchased from Sigma-Aldrich (USA) and PEI solution was prepared for transfection [26-31].

\section{Plasmid Construction and Transfection}

Generation of p3xFLAG-CMV10-PCP was described previously [18]. Constructs expressing RIG-I, MDA5, inhibitor of nuclear factor kappa-B kinase subunit epsilon (IKKع) and mitochondrial antiviral-signaling protein (MAVS) were provided by Dr. Soon Bong Hwang. Untagged PCP was generated using EcoRV and XhoI restriction enzyme sites in the multi-cloning site of the pcDNA3.1. GFP-tagged PCP construct was generated by cloning HEV PCP gene into the pEGFP-C1 vector using EcoRI and XbaI sites. All plasmids were sequence-verified (Macrogen, Korea). DNA-PEI complex was made at a ratio of 1:2 for $30 \mathrm{~min}$ in the absence of FBS and antibiotics. DNA-PEI complexes were transfected into HEK 293T cells and incubated for $24 \mathrm{~h}$ before cell harvest for luciferase reporter assay [18].

\section{Luciferase Reporter Assay.}

IFN- $\beta$-luciferase (IFN- $\beta$-luc) reporter construct and betagalactosidase ( $\beta$-gal) plasmid in combination with PCP-expressing plasmids and/or constructs, which express MDA5, RIG-I, IKKع, or MAVS, were transfected as described before [18]. At $24 \mathrm{~h}$ posttransfection, cells were lysed using reporter lysis $5 \mathrm{X}$ buffer (Promega, USA). Activities of luciferase in each transfected sample were determined using luciferase assay system according to the manufacturer's instructions (Promega, USA) using the Glomax (Promega, USA). Luminescence of firefly luciferase was normalized by $\beta$-gal activity.

\section{Statistical Analysis}

The statistical significance was analyzed by the Student's $t$ test. $P$ value smaller than $0.05(p<0.05)$ was interpreted as statistically significant [32]. Data are shown as one representative example from at least two independent experiments.

\section{Results}

HEV PCP Inhibits Induction of IFN- $\beta$ and NF- $\kappa B$ Activation in a Dose-Responsive Manner

Previously, we showed that PCP inhibited over $70 \%$ of poly(I:C)-mediated induction of IFN- $\beta$ [18]. To investigate if PCP inhibits MDA5-mediated activation of IFN signaling cascades, HEK293T cells were co-transfected with IFN- $\beta$ luc (Fig. 1A) or NF-kB-luc (Fig. 1B), $\beta$-gal, and MDA5expressing plasmid with an increasing amount of PCPexpressing construct $(0,0.5,1,2 \mu \mathrm{g}$ DNA). Interestingly, both of MDA5-mediated activation of IFN- $\beta$ and NF- $\kappa B$ promoter activities were strongly inhibited (Figs. 1A and 1B) in a dose-dependent manner. In addition, as the cellular viability after transfection with various plasmids was comparable among all experimental groups, the loss of signaling activation did not seem to be caused by damage to cell membranes and/or cellular activities by experimental manipulations (Fig. 1C). Therefore, taken together, it is reasonable to conclude that HEV PCP inhibits activation of IFN- $\beta$ and NF- $\kappa \mathrm{B}$ signaling. 
A

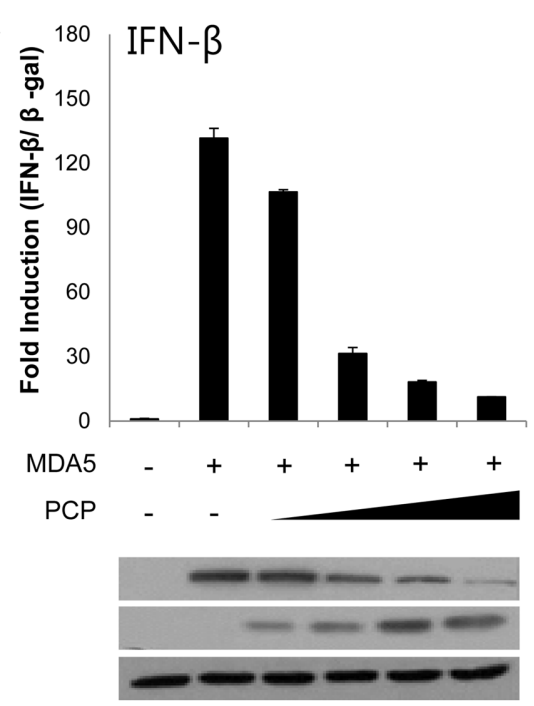

B

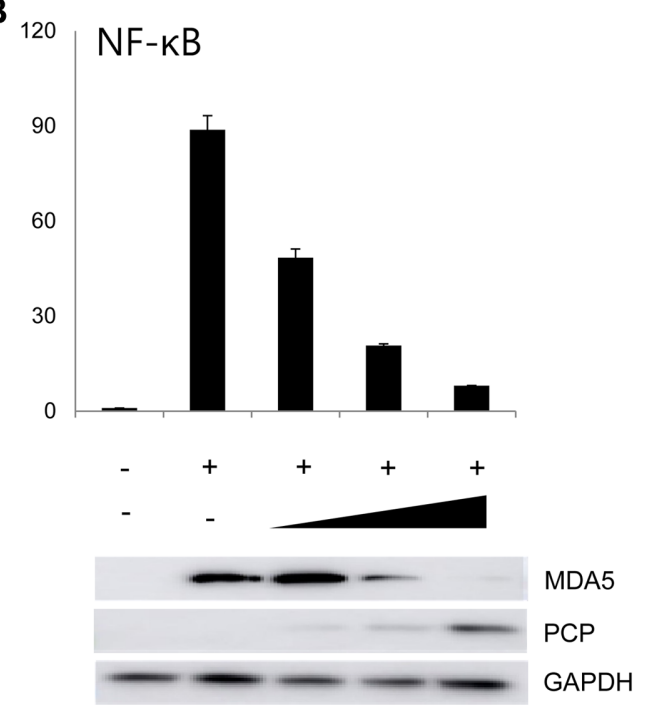

C

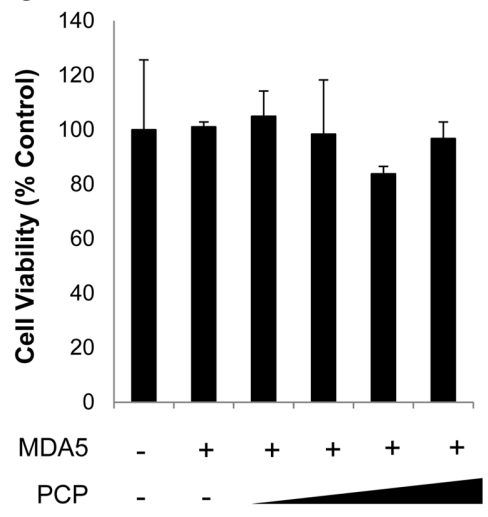

Fig. 1. HEV PCP inhibits induction of IFN- $\beta$ and NF- $\mathrm{KB}$ activation in a dose-responsive manner.

HEK293T cells were co-transfected with IFN- $\beta$-luc (A) or NF- $\kappa$ B-luc (B) together with $\beta$-gal- and MDA5-expressing plasmids with an increasing amount of PCP-expressing construct. At $24 \mathrm{~h}$ post-transfection, cells were lysed and luciferase activities were determined. A separate set of transfected cells were analyzed for cell viability (C). Viability of each transfected cell was measured by MTT assay and normalized to that of empty vector-transfected cells.

HEV PCP Inhibits Induction of IFN- $\beta$ Signaling Regardless of the Nature and Presence/Absence of a Tag Fused to PCP Protein

Expression of a protein in fusion to a tag allows detection of the protein of interest. However, the presence of a tag may influence the structure of the protein of interest, affecting its function in the cell. Therefore, it is possible that the inhibitory activity of FLAG-PCP (Fig. 1) may be an artifact of overexpression PCP in fusion to FLAG tag at the $\mathrm{N}$-terminus. Thus, it is of paramount importance to confirm the inhibitory function of PCP in the presence of different tags or in the absence of a tag. Here, we tested GFP-fused
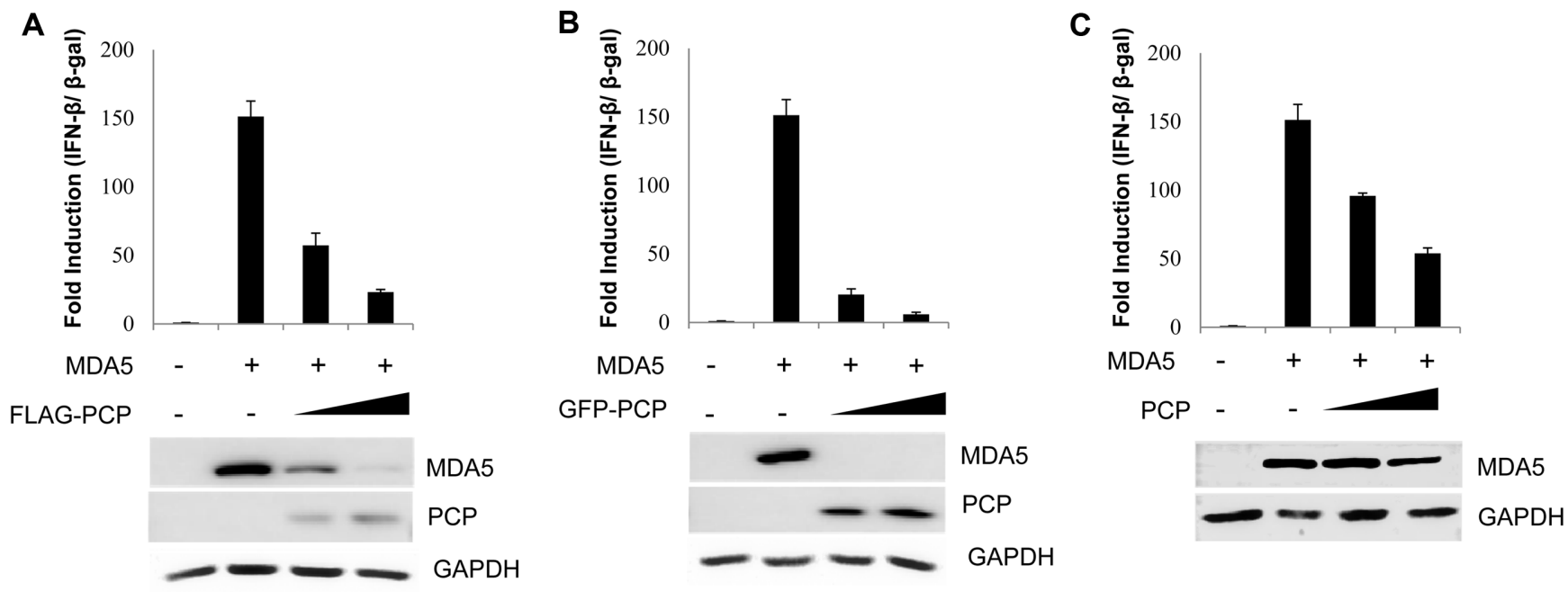

Fig. 2. HEV PCP inhibits induction of IFN- $\beta$ irregardless of the nature and presence/absence of a tag.

HEK293T cells were co-transfected with IFN- $\beta$-luc, $\beta$-gal- and MDA5-expressing plasmids with an increasing amount of PCP-expressing construct: FLAG-tagged PCP (A), GFP-tagged PCP (B) or un-tagged PCP (C). At $24 \mathrm{~h}$ post-transfection, cells were lysed and luciferase activities were determined. 
or untagged PCP for their efficacy to inhibit type I IFN signaling. Of note, GFP-fused PCP displayed as strong inhibitory activity as that of FLAG-tagged PCP (Figs. 2A and $2 \mathrm{~B}$ ), suggesting that the nature/sequence of a tag may not affect the inhibitory activity of HEV PCP. To further confirm that HEV PCP has inhibitory activity on type I IFN, we constructed and tested the function of untagged PCP for its inhibitory effect on the IFN signaling (Fig. 2C). Untagged PCP did inhibit MDA5-mediated activation of IFN promoter activity in a dose-responsive manner albeit to a lesser degree than that of FLAG-tagged PCP (Fig. 2A). Taken together, it is reasonable to conclude that HEV PCP inhibits MDA5-induced activation of IFN $-\beta$ signaling.

\section{HEV PCP Inhibits IFN- $\beta$ Signaling Induced by Poly(I:C) Treatment or Sendai Virus Infection}

Poly(I:C) treatment and Sendai virus infection are known as strong inducers of type I IFN signaling. To examine whether HEV PCP is capable of inhibiting IFN signaling induced by those stimuli, HEK293T cells, co-transfected with MDA5 and FLAG-PCP plasmids, were treated with $5 \mu \mathrm{g} / \mathrm{ml}$ poly(I:C) (Fig. 3A) or infected with $100 \mathrm{HAU} / \mathrm{ml}$ Sendai virus (Fig. 3B). In both cases, MDA5 alone induced roughly $50-100$ fold induction of IFN- $\beta$ signaling. However, in combination of MDA5 and poly(I:C) or Sendai virus, fold induction reached as high as 450 fold and 300 fold, respectively. In the presence of HEV PCP, highly-induced IFN signaling was strongly inhibited as in the cells stimulated only with MDA5. These data suggest that HEV PCP may be able to inhibit type I IFN signaling activated by host recognition of viral genome (what poly(I:C) mimics) or in the context of viral infection (what Sendai virus mimics). It is interesting to note that phosphorylated IRF3 is decreased in the presence of PCP (Fig. 3B), suggesting that reduction of IFN signaling by PCP may result from the decrease in IRF3 phosphorylation.

HEV PCP Inhibits Induction of IFN- $\beta$ by MDA5, RIG-I, and TBK1 but Not by MAVS or IKK $\varepsilon$

To investigate which molecules of the type I IFN signaling cascades are affected by HEV PCP, each immune gene expressing constructs was co-transfected into HEK293T cells together with a plasmid expressing HEV PCP (Fig. 4). It is interesting to note that HEV PCP inhibits RIG-I/TBK1 -induced activation of IFN- $\beta$ signaling as expected $[19,33$, 34]. In addition, as the present study defined, HEV PCP strongly inhibited MDA5-mediated IFN- $\beta$ signaling. However, HEV PCP did not significantly affect MAVS- or
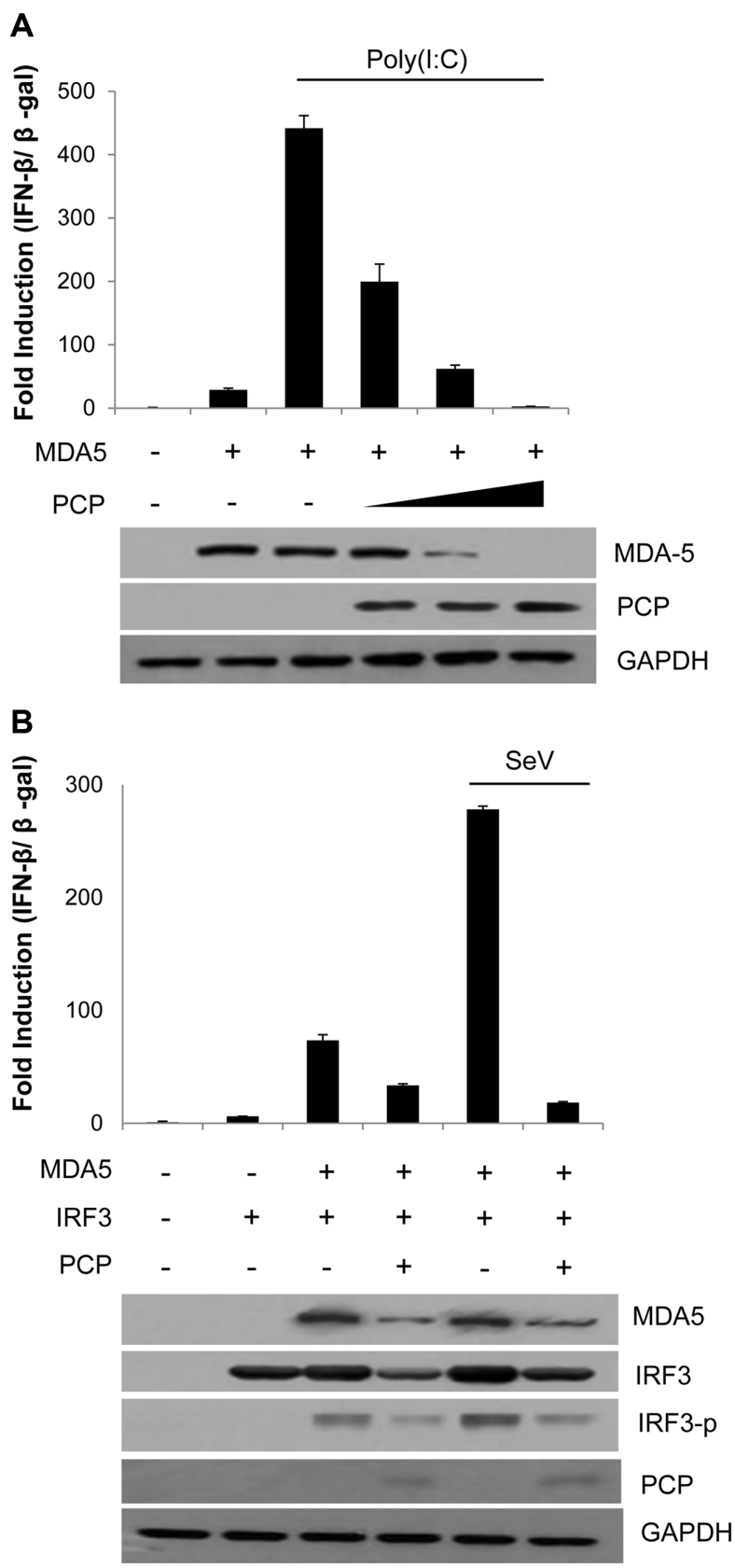

Fig. 3. HEV PCP inhibits induction of IFN- $\beta$ by poly(I:C) treatment or Sendai virus infection.

HEK293T cells were transfected IFN- $\beta$-luc, $\beta$-gal, and plasmids expressing MDA5 or PCP. At $24 \mathrm{~h}$ post-transfection, cells were either treated with poly(I:C) (A) or infected with Sendai virus (B) for $12 \mathrm{~h}$ before subjected to luciferase assay.

IKK $\varepsilon$-mediated activation of IFN- $\beta$ signaling, suggesting that HEV PCP may have broad but selective targets for the inhibition of type I IFN. 
A
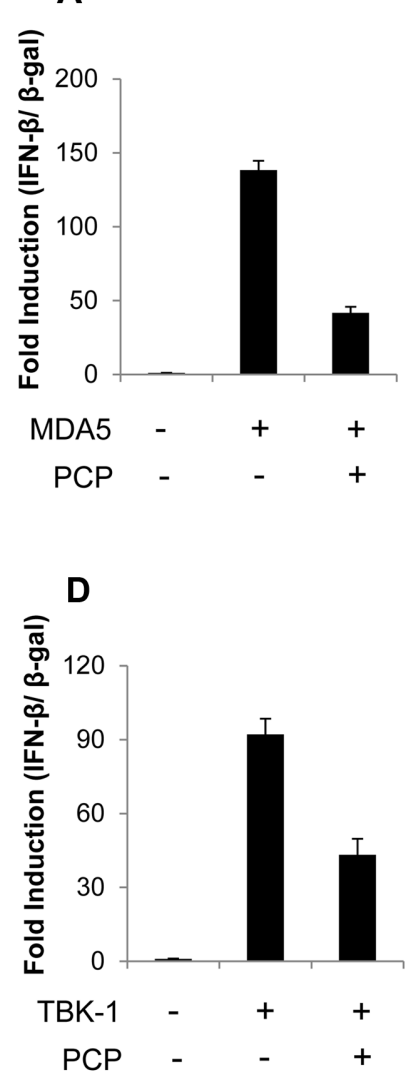

B

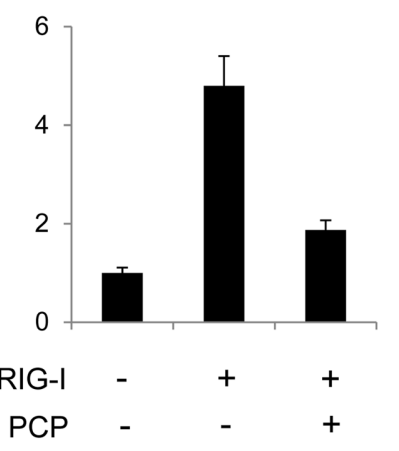

E

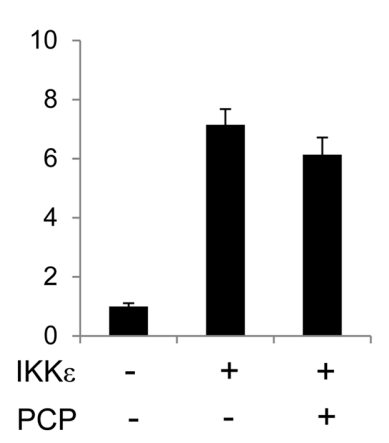

C

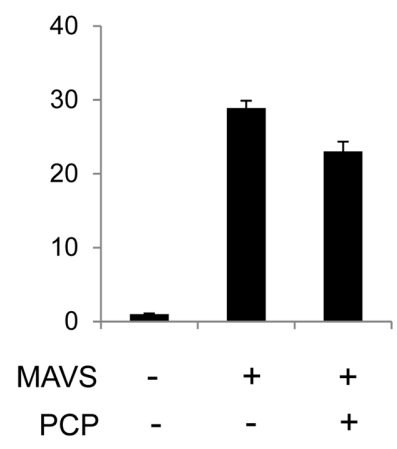

Fig. 4. HEV PCP inhibits induction of IFN- $\beta$ by MDA5, RIG-I, and TBK1 but not by MAVS or IKKe.

HEK293T cells were transfected IFN- $\beta$-luc, $\beta$-gal, and plasmids expressing PCP and various immune genes as indicated in the Figures. At $24 \mathrm{~h}$ post-transfection, cells were harvested and subjected to luciferase assay.

\section{Discussion}

Upon virus infection, host cells rapidly mount type I IFN responses. Pattern recognition receptors (PRRs) play an important role at the early stage of infection [3, 13, 35-42]: MDA5, RIG-I, and toll-like receptors (TLR). MDA5 and RIG-I are known to sense the RNA genome of the invading pathogens. However, there seem to be subtle differences in what these two PRRs recognize [43, 44]. RIG-I recognizes relatively short RNA's with $5^{\prime}$ triphosphate with the end blunted. On the other hand, MDA5 recognizes long RNA's without imposed restrictions on the nature and structure of the RNA molecules that it recognizes. The RNA genome of the invading viruses is recognized by MDA5 or RIG-I in the cytoplasm. Activation of MDA5 and RIG-I leads to aggregation of MAVS on the mitochondrial outer membrane [45-47], which becomes resistant to proteases and thus stabilized/activated to induce down-stream signaling molecules such as TBK1 and IKKe. Activated IKKe in turn phosphorylate and induce dimerization of IRF3 [48-50]. Dimerized IRF3 is translocated into the nucleus and together with NF- $\kappa \mathrm{B}$ activates transcription of IFN- $\beta$ mRNA. Therefore, viruses have evolved a slew of different strategies to evade recognition of their genomes by MDA5 and RIG-I [3]. Investigation and understanding of how viruses escape immune surveillance and recognition in the cytoplasm is thus critical to win the arms race between human beings and pathogens.

Previously, we screened the whole panel of HEV genes cloned into an expression vector and showed that HEV PCP inhibits type I interferon responses [18]. As it is already known that HEV PCP down-regulates K63-lined polyubiquitination of the RIG-I repressor domain [19, 33, 34], we sought to investigate whether the other pattern recognition receptor, namely MDA5, is regulated by $\mathrm{HEV}$ PCP. Interestingly, MDA5-mediated activation of IFN- $\beta$ reporter activity was over $90 \%$ inhibited and it is likely due to low levels of MDA5 protein expression (Figs. 1-4). 
Molecular mechanism(s) of down-regulation of MDA5 protein levels are currently being sought. As the signals initiated by MDA5 recognition of viral RNA's leads to IRF3 phosphorylation, phosphorylation status of IRF3 was investigated. As expected, IRF3 phosphorylation was severely impaired in the presence of PCP (Fig. 4B). Thus, low levels of IFN- $\beta$ induction in the presence of PCP is likely due to low level phosphorylation of IRF3. On the other hand, to fully induce IFN- $\beta$ expression, both IRF3 and NF- $\mathrm{KB}$ are required to be activated and translocated into the nucleus. Therefore, analysis of the activation status of NF- $\mathrm{KB}$ is prerequisite to better understand $\mathrm{PCP}$-mediated impairment of IFN- $\beta$ induction. Of note, MDA5-mediated NF- $\mathrm{BB}$ activation was sharply decreased by PCP (Fig. 1B), suggesting that $\mathrm{PCP}$ is capable of regulating both arms of IFN- $\beta$ signaling: IRF3 and NF- $\kappa B$.

As HEV PCP-specific antibodies are not available, we utilized FLAG-PCP and analyzed its expression by antiFLAG antibodies (Figs. 1-4). Caveats of those analyses include the possibility that PCP fusion to a tag may influence folding of PCP and thus its structure and function. Therefore, we fused eGFP to HEV PCP, the size of which is much bigger than a FLAG tag (Fig. 2B) to investigate whether the size and nature of a tag would affect the function of PCP. Fig. 2B clearly demonstrates that eGFP-PCP fusion protein has the same levels of inhibitory effects on MDA5-mediated IFN- $\beta$ induction. Furthermore, untagged PCP inhibited IFN- $\beta$ induction activated by MDA5 (Fig. 2C). Taken together, it is reasonable to conclude that $\mathrm{PCP}$, in a native form or in a fusion, functions to inhibit MDA5-mediated activation of IFN- $\beta$ expression.

The lack of a robust cell culture system for HEV makes it difficult to test if HEV PCP has inhibitory effects on MDA5mediated activation of type I IFN responses in the context of viral infection. Hence, we investigated if HEV PCP is capable of inhibiting type 1 IFN responses activated by poly(I:C), a mimic of RNA virus infection. Poly(I:C)induced activation was severely impaired by HEV PCP. The same was true with that of $\mathrm{SeV}$ infection. Taken together, it is likely that PCP, upon HEV infection in cells, counteracts viral genome sensing by MDA5, thereby downregulating type I IFN signaling activation.

In summary, in the present study, we showed that HEV PCP impairs MDA5-mediated activation of IFN- $\beta$ induction. These results further expand the list of HEV-encoded antagonists of the host innate responses and delineation of molecular mechanisms of PCP-mediated inhibition will pave the way to development of effective anti-HEV therapeutics.

\section{Acknowledgment}

This research was supported by HI15C3039 through the Korea Health Industry Development Institute (KHIDI) funded by the Korean Ministry of Health and Welfare and by a grant from the Center for Analytical Research of Disaster Science of Korea Basic Science Institute (C38711) to J. Kwon.

\section{Conflict of Interest}

The authors have no financial conflicts of interest to declare.

\section{Reference}

1. Forni D, Cagliani R, Clerici M, Sironi M. 2018. Origin and dispersal of Hepatitis E virus. Emerg. Microbes Infect. 7: 11.

2. Tam AW, Smith MM, Guerra ME, Huang CC, Bradley DW, Fry KE, et al. 1991. Hepatitis E virus (HEV): molecular cloning and sequencing of the full-length viral genome. Virology 185: 120-131.

3. Kang S, Myoung J. 2017. Host innate immunity against Hepatitis E virus and viral evasion mechanisms. J. Microbiol. Biotechnol. 27: 1727-1735.

4. Kumar S, Subhadra S, Singh B, Panda BK. 2013. Hepatitis E virus: the current scenario. Int. J. Infect. Dis. 17: e228-233.

5. Krawczynski K. 1993. Hepatitis E. Hepatology 17: 932-941.

6. Wong DC, Purcell RH, Sreenivasan MA, Prasad SR, Pavri KM. 1980. Epidemic and endemic hepatitis in India: evidence for a non-A, non-B hepatitis virus aetiology. Lancet 2: 876-879.

7. Khuroo MS. 1980. Study of an epidemic of non-A, non-B hepatitis. Possibility of another human hepatitis virus distinct from post-transfusion non-A, non-B type. Am. J. Med. 68: 818-824.

8. Reyes GR, Purdy MA, Kim JP, Luk KC, Young LM, Fry KE, et al. 1990. Isolation of a cDNA from the virus responsible for enterically transmitted non-A, non-B hepatitis. Science 247: 1335-1339.

9. Jilani N, Das BC, Husain SA, Baweja UK, Chattopadhya D, Gupta RK, et al. 2007. Hepatitis E virus infection and fulminant hepatic failure during pregnancy. J. Gastroenterol. Hepatol. 22: 676-682.

10. Navaneethan U, Al Mohajer M, Shata MT. 2008. Hepatitis E and pregnancy: understanding the pathogenesis. Liver Int. 28: 1190-1199.

11. Theofilopoulos AN, Baccala R, Beutler B, Kono DH. 2005. Type I interferons (alpha/beta) in immunity and autoimmunity. Annu. Rev. Immunol. 23: 307-336.

12. Zitvogel L, Galluzzi L, Kepp O, Smyth MJ, Kroemer G. 2015. Type I interferons in anticancer immunity. Nat. Rev. 
Immunol. 15: 405-414.

13. Kim N, Now H, Nguyen NTH, Yoo JY. 2016. Multilayered regulations of RIG-I in the anti-viral signaling pathway. J. Microbiol. 54: 583-587.

14. Schmidt ME, Varga SM. 2017. Modulation of the host immune response by respiratory syncytial virus proteins. J. Microbiol. 55: 161-171.

15. Draenert R, Frater J, Prado JG. 2012. Virus immune evasion: new mechanism and implications in disease outcome. Adv. Virol. 2012: 490549.

16. Senba M, Mori N. 2012. Mechanisms of virus immune evasion lead to development from chronic inflammation to cancer formation associated with human papillomavirus infection. Oncol Rev. 6(2): e17.

17. Uddin MB, Lee BH, Nikapitiya C, Kim JH, Kim TH, Lee HC, et al. 2016. Inhibitory effects of bee venom and its components against viruses in vitro and in vivo. J. Microbiol. 54: 853-866.

18. Kang S, Choi C, Choi I, Han KN, Roh SW, Choi J, et al. 2018. Hepatitis E virus methyltransferase inhibits type I interferon induction by targeting RIG-I. J. Microbiol. Biotechnol. doi: 10.4014/jmb.1808.08058 [Epub ahead of print]

19. Nan Y, Yu Y, Ma Z, Khattar SK, Fredericksen B, Zhang YJ. 2014. Hepatitis $E$ virus inhibits type I interferon induction by ORF1 products. J. Virol. 88: 11924-11932.

20. Surjit M, Varshney B, Lal SK. 2012. The ORF2 glycoprotein of hepatitis $\mathrm{E}$ virus inhibits cellular NF-kappaB activity by blocking ubiquitination mediated proteasomal degradation of IkappaBalpha in human hepatoma cells. BMC Biochem. 13: 7.

21. He M, Wang M, Huang $Y$, Peng W, Zheng Z, Xia N, et al. 2016. The ORF3 protein of genotype 1 Hepatitis E virus suppresses TLR3-induced NF-kappaB signaling via TRADD and RIP1. Sci. Rep. 6: 27597.

22. Choi S, Park H, Minelko M, Kim EK, Cho MR, Nam JH. 2017. Recombinant adeno-associated virus expressing truncated IK cytokine diminishes the symptoms of inflammatory arthritis. J. Microbiol. Biotechnol. 27: 1892-1895.

23. Hamid FB, Kim J, Shin CG. 2017. Characterization of prototype foamy virus infectivity in transportin 3 knockdown human 293t cell line. J. Microbiol. Biotechnol. 27: 380-387.

24. Lee JM, Cho JB, Ahn HC, Jung W, Jeong YJ. 2017. A novel chemical compound for inhibition of SARS coronavirus helicase. J. Microbiol. Biotechnol. 27: 2070-2073.

25. Liu X, Dong Y, Wang J, Li L, Zhong Z, Li YP, et al. 2017. VSV-G viral envelope glycoprotein prepared from Pichia pastoris enhances transfection of DNA into animal cells. J Microbiol Biotechnol. 27: 1098-1105.

26. Ahn HS, Han SH, Kim YH, Park BJ, Kim DH, Lee JB, et al. 2017. Adverse fetal outcomes in pregnant rabbits experimentally infected with rabbit hepatitis E virus. Virology 512: 187-193.

27. Cho M, Myoung J. 2015. OX40 and 4-1BB downregulate Kaposi's sarcoma-associated herpesvirus replication in lymphatic endothelial cells, but 4-1BB and not OX40 inhibits viral replication in B-cells. J. Gen. Virol. 96: 3635-3645.

28. Fu B, Kuang E, Li W, Avey D, Li X, Turpin Z, et al. 2015. Activation of p90 ribosomal S6 kinases by ORF45 of Kaposi's sarcoma-associated herpesvirus is critical for optimal production of infectious viruses. J. Virol. 89: 195-207.

29. Gillen J, Li W, Liang Q, Avey D, Wu J, Wu F, et al. 2015. A survey of the interactome of Kaposi's sarcoma-associated herpesvirus ORF45 revealed its binding to viral ORF33 and cellular USP7, resulting in stabilization of ORF33 that is required for production of progeny viruses. J. Virol. 89: 4918-4931.

30. Ha S, Choi IS, Choi C, Myoung J. 2016. Infection models of human norovirus: challenges and recent progress. Arch. Virol. 161: 779-788.

31. Kang HS, Myoung J, So EY, Bahk YY, Kim BS. 2016. Transgenic expression of non-structural genes of Theiler's virus suppresses initial viral replication and pathogenesis of demyelination. J. Neuroinflammation 13: 133.

32. Lee M, Seo DJ, Seo J, Oh H, Jeon SB, Ha SD, et al. 2015. Detection of viable murine norovirus using the plaque assay and propidium-monoazide-combined real-time reverse transcription-polymerase chain reaction. J. Virol. Methods 221: 57-61.

33. Karpe YA, Lole KS. 2011. Deubiquitination activity associated with hepatitis $\mathrm{E}$ virus putative papain-like cysteine protease. J. Gen. Virol. 92: 2088-2092.

34. Oshiumi H, Miyashita M, Matsumoto M, Seya T. 2013. A distinct role of Riplet-mediated K63-Linked polyubiquitination of the RIG-I repressor domain in human antiviral innate immune responses. PLoS Pathog. 9: e1003533.

35. Akira S, Uematsu S, Takeuchi O. 2006. Pathogen recognition and innate immunity. Cell 124: 783-801.

36. Kang S, Myoung J. 2017. Primary lymphocyte infection models for KSHV and its putative tumorigenesis mechanisms in B cell lymphomas. J. Microbiol. 55: 319-329.

37. Medzhitov R. 2007. Recognition of microorganisms and activation of the immune response. Nature 449: 819-826.

38. Lee BH, Chathuranga K, Uddin MB, Weeratunga P, Kim MS, Cho WK, et al. 2017. Coptidis Rhizoma extract inhibits replication of respiratory syncytial virus in vitro and in vivo by inducing antiviral state. J. Microbiol. 55: 488-498.

39. Seong RK, Choi YK, Shin OS. 2016. MDA7/IL-24 is an antiviral factor that inhibits influenza virus replication. J. Microbiol. 54: 695-700.

40. Lai HC, Horng YT, Yeh PF, Wang JY, Shu CC, Lu CC, et al. 2016. The assessment of host and bacterial proteins in sputum from active pulmonary tuberculosis. J. Microbiol. 54: 761-767.

41. Weeratunga P, Uddin MB, Kim MS, Lee BH, Kim TH, Yoon JE, et al. 2016. Interferon-mediated antiviral activities of Angelica tenuissima Nakai and its active components. J. Microbiol. 54: 57-70.

42. Weeratunga $\mathrm{P}$, Herath TUB, Kim TH, Lee HC, Kim JH, 
Lee BH, et al. 2017. Dense Granule Protein-7 (GRA-7) of Toxoplasma gondii inhibits viral replication in vitro and in vivo. J. Microbiol. 55: 909-917.

43. Loo YM, Fornek J, Crochet N, Bajwa G, Perwitasari O, Martinez-Sobrido L, et al. 2008. Distinct RIG-I and MDA5 signaling by RNA viruses in innate immunity. J. Virol. 82: 335-345.

44. Takeuchi O, Akira S. 2010. Pattern recognition receptors and inflammation. Cell 140: 805-820.

45. Kawai T, Takahashi K, Sato S, Coban C, Kumar H, Kato H, et al. 2005. IPS-1, an adaptor triggering RIG-I- and Mda5mediated type I interferon induction. Nat. Immunol. 6: 981988.

46. Meylan E, Curran J, Hofmann K, Moradpour D, Binder M, Bartenschlager $\mathrm{R}$, et al. 2005. Cardif is an adaptor protein in the RIG-I antiviral pathway and is targeted by hepatitis C virus. Nature 437: 1167-1172.

47. Seth RB, Sun L, Ea CK, Chen ZJ. 2005. Identification and characterization of MAVS, a mitochondrial antiviral signaling protein that activates NF-kappaB and IRF 3. Cell 122: 669682.

48. Grandvaux N, Servant MJ, tenOever B, Sen GC, Balachandran S, Barber GN, et al. 2002. Transcriptional profiling of interferon regulatory factor 3 target genes: direct involvement in the regulation of interferon-stimulated genes. J. Virol. 76: 5532-5539.

49. Honda K, Takaoka A, Taniguchi T. 2006. Type I interferon [corrected] gene induction by the interferon regulatory factor family of transcription factors. Immunity 25: 349-360.

50. Liu S, Cai X, Wu J, Cong Q, Chen X, Li T, et al. 2015. Phosphorylation of innate immune adaptor proteins MAVS STING, and TRIF induces IRF3 activation. Science 347: aaa2630. 